\title{
Sharps-handling practices among junior surgical residents: a video analysis
}

\author{
DavidTso, MD* \\ Monica Langer, $\mathrm{MD}^{\dagger}$ \\ Geoff K. Blair, MD ${ }^{\dagger}$ \\ Sonia Butterworth, $\mathrm{MD}^{\dagger}$
}

From the *University of British Columbia and the $+B C$ Children's Hospital, Division of Pediatric Surgery, University of British Columbia, Vancouver, BC

Accepted for publication

Sept. 6, 2011

\author{
Correspondence to: \\ S. Butterworth \\ K0-113, ACB \\ 4480 Oak St. \\ Vancouver BC V6H 3V4 \\ sbutterworth@cw.bc.ca
}

DOI: $10.1503 /$ cjs.031210
Background: Although "universal precautions" are standard for sharps handling, there has been poor compliance among surgeons. We used video analysis to assess sharps handling practices among junior surgical residents.

Methods: Postgraduate year (PGY)-2 general surgery and PGY-1 plastic surgery residents were videotaped performing pediatric inguinal hernia repairs. For each procedure, the resident was the principal operator, with the attending surgeon assisting. Retrospective assessment of safe and unsafe sharps handling was determined based on published guidelines. We assessed safety performance in personal sharps tasks, passage of sharps and verbal notification regarding sharps. Data was analyzed using descriptive statistics.

Results: Data were collected from 18 residents' videos (4 plastic surgery, 14 general surgery). Residents safely performed sharps tasks, passed and verbally notified about sharps an average of $69.2 \%, 93.2 \%$ and $9.9 \%$ of the time, respectively. Suture needle manipulation was handled safely $56.2 \%$ of the time (mean 4.4 safe v. 4.3 unsafe actions). Surgical residents demonstrated a safe suture tying technique in $91.8 \%$ of cases, proper tissue retraction in $85.2 \%$ and safe handling of injection needles in $72.2 \%$ of cases. When assessing the safety performance of the surgical team, attending surgeons acting as surgical assistants safely passed sharps $80.0 \%$ of the time, while scrub nurses demonstrated safe passing at all times. Attending surgeons used verbal notification when passing sharps $22.7 \%$ of the time, while scrub nurses verbally notified the team $4.3 \%$ of the time.

Conclusion: Junior surgical residents consistently passed sharps safely. Personal sharps tasks were less likely to be performed safely, and only a minority of residents verbally notified the team about sharps placement.

Contexte : Même si les «précautions universelles » constituent la norme pour la manipulation sécuritaire des objets pointus ou tranchants, on constate que les chirurgiens semblent peu s'y conformer. Nous avons utilisé une analyse vidéo pour évaluer les pratiques en ce qui concerne la manipulation des objets pointus ou tranchants chez les résidents juniors en chirurgie.

Méthodes : Des résidents en chirurgie générale (R2) et en chirurgie plastique (R1) ont été filmés pendant des interventions pour réparation d'hernie inguinale chez des enfants. Pour chacune de ces interventions, le résident avait le rôle de chirurgien principal, le chirurgien traitant agissant alors à titre d'assistant. L'évaluation rétrospective de la manipulation sécuritaire ou non des objets pointus ou tranchants a été effectuée en regard des lignes directrices publiées. Nous avons évalué les résultats sur 3 plans concernant la sécurité : tâches personnelles accomplies avec des objets pointus ou tranchants, transfert des objets pointus et avertissements verbaux les concernant. Des statistiques descriptives ont servi à l'analyse des données.

Résultats : Les données ont été recueillies à partir des vidéos de 18 résidents (4 en chirurgie plastique, 14 en chirurgie générale). Les résidents ont appliqué les principes de sécurité en effectuant des tâches avec des objets pointus ou tranchants, en les transférant ou en donnant des avertissements verbaux dans 69,2\%,93,2\% et 9,9\% des cas, en moyenne, respectivement. La manipulation des aiguilles pour suture a été sécuritaire dans 56,2 \% des cas (moyenne 4,4 manœuvres sécuritaires c. 4,3 manœuvres non sécuritaires). Les résidents en chirurgie ont utilisé une technique sécuritaire lors des sutures dans $91,8 \%$ des cas, une technique de rétraction tissulaire adéquate dans $85,2 \%$ des cas et une manipulation sécuritaire des aiguilles à injection dans 72,2\% des cas. Pour ce qui est de l'évaluation du rendement de l'équipe chirurgicale au plan de la sécurité, les chirurgiens traitants agissant comme assistants ont transféré les 
objets pointus et tranchants de manière sécuritaire dans 80,0 \% des cas, tandis que les infirmières en chirurgie se sont acquittées de cette tâche de manière sécuritaire en toute occasion. Les chirurgiens traitants ont utilisé les avertissements verbaux lors du transferts des objets pointus ou tranchants dans $22,7 \%$ des cas, tandis que les infirmières en chirurgie ont averti l'équipe dans $4,3 \%$ des cas.

Conclusion : Les résidents juniors en chirurgie ont à chaque fois transféré les objets pointus ou tranchants de manière sécuritaire. Les tâches personnelles effectuées avec ces objets étaient moins susceptibles d'être effectuées de manière sécuritaire et seulement une minorité de résidents ont averti verbalement l'équipe de la localisation des objets pointus ou tranchants.

njury due to sharp instruments (sharps) poses an occupational risk to health care professionals because of the potential exposure to harmful agents, hence the importance of implementing safe sharps-handling procedures. Although the scope of total sharps injuries is not fully known, the U.S. National Institute for Occupational Safety and Health has estimated that between 600000 and 800000 percutaneous injuries involving health care workers occur annually. ${ }^{1}$ The occupational risk of exposure to blood-borne pathogens has increased in recent years, especially in large urban teaching hospitals with greater numbers of HIV and hepatitis $\mathrm{C}$ patients. ${ }^{2}$

Even though "universal precautions" represent the standard of care, the literature demonstrates poor compliance among surgeons. ${ }^{3}$ In addition, many surgeons feel that these standards are inadequate to properly minimize the risk to the surgical team in the operating room (OR). ${ }^{4,5}$ Analysis of sharps-handling practices among surgical residents is infrequently published; however, literature examining injuries demonstrates very high injury rates despite only $49 \%$ of injuries being reported. ${ }^{6}$ Injuries to surgeons and first assistants account for $59 \%$ of all sharps-related injuries in the perioperative setting. ${ }^{7}$ An overwhelming majority of surgical residents sustain a needle stick injury at some point during their training. Senior and chief residents experience a significantly lower incidence of injury than junior residents. ${ }^{8}$ A survey of surgical residents at 17 medical centres found that $99 \%$ of surgeons in training had sustained a needle stick injury by their final year of training. ${ }^{6}$ Of those injuries, $53 \%$ involved patients with a history of infection with HIV, hepatitis B or C, or intravenous drug use.

In differentiating the mechanisms of injury due to sharps, most injuries are inflicted by suture needles, followed by sharp instruments and least frequently by hollowbore needles. ${ }^{9,10}$ A survey of surgical residents found that most percutaneous injuries were self-inflicted (66.7\%) and occurred during wound closure $(72.7 \%) .{ }^{11}$ Injuries from suture needles occur when loading the suture needle into the driver or repositioning the needle with fingers during hand-to-hand passing of sharps devices between OR team members and during wound closure when the needle is manipulated with fingers. ${ }^{5}$ Injuries also occur during retraction of tissue with hands, when a surgeon sews toward his or her own hand or the assistant's hand and when tying a suture while the needle is attached. ${ }^{5}$ In addition, there is risk for injury when a suture is left unattended on the operative field after use.

As part of resident evaluation, video playback of surgical procedures has been incorporated in training surgical residents at our institution. Video playback in surgery has been used as an education tool for both trauma resuscitations ${ }^{12}$ and laparoscopic operative performance. ${ }^{13,14}$ It has been found to be useful in open operations for correcting isolated errors. ${ }^{15}$ When compared with traditional verbal feedback, videotape review has been found to be superior in teaching trauma resuscitation, leading to ongoing and sustained performance improvement in multiple areas. ${ }^{12}$ To our knowledge, there are no studies that employ video analysis of surgical performance to assess sharps-handling techniques.

This purpose of the present study was to determine sharp instrument handling safety performance among junior surgical residents acting as the primary operator during surgery. The frequency of safe sharps passing and use of verbal notification while passing to surgical team members were also assessed. In addition, a secondary aim was to measure the sharps safety performance of the OR team, including the surgical assistant (attending surgeon) and the scrub nurse.

\section{Methods}

A review of videotaped, open, indirect inguinal hernia repairs performed from 2001 to 2005 by junior surgical residents was undertaken with institutional review board approval and with the consent of the patients, families, OR staff and residents. The procedures all took place at a tertiary children's hospital during a 2-month rotation of both postgraduate year (PGY)-2 general surgery and PGY-1 plastic surgery residents. For each procedure, the resident was the principal operator, with the attending surgeon assisting. The videos were originally intended to be used to provide feedback on the residents' surgical technique as part of an educational exercise.

We assessed safe and unsafe sharps handling based on the Association of Perioperative Nurses guidelines, ${ }^{5}$ which were developed in response to evaluation of the factors 
associated with sharps injuries sustained by the surgical team during operations. Resident safety performance was scored in 3 areas: personal sharps tasks, passage of sharps and verbal notification regarding sharps (Table 1). We also assessed the use of the hands-free technique (HFT) during the procedures. The HFT is defined as "a previously agreed location on the field where sharps are placed from which the surgeon or scrub can retrieve them. So hand-tohand passing of sharps is limited." 16

The scoring was done by a single individual (D.T.) who was blinded to PGY and the year of the video. This individual was an undergraduate medical student at the time of the study and underwent training in the OR, where he scrubbed in during cases and observed safe sharp-handling practices. Inguinal hernia repairs accounted for the majority of the surgical exposure, but the scorer was familiarized with many other surgical procedures. Each of the unsafe sharpshandling practices was demonstrated by a surgeon (S.B.) using clean instruments separate from patient care. Standardized safe and unsafe sharps events were videotaped, and the tapes were used as an additional resource. All procedure videos were reviewed at least twice (by D.T.) to ensure all sharps-handling events were evaluated. All actions involving sharps were documented by the first reviewer, and each sharps event was viewed by a second reviewer (S.B.) to ensure the action was accurately scored as safe, unsafe or incomplete data (e.g., obstructed view of operative field, unable to understand verbalization regarding sharps). If there was disagreement about the designation of a sharps action, the surgeon's score was used. The sharps-handling practices of the attending surgeon (who was assisting) as well as the scrub nurse were evaluated in the same fashion.

The total number of events during a case was recorded

Table 1. Definitions of safe and unsafe sharps tasks used to assess safety performance

\begin{tabular}{|c|c|c|}
\hline Sharps task & Safe & Unsafe \\
\hline \multicolumn{3}{|l|}{ Personal } \\
\hline Suture needle & $\begin{array}{l}\text { Using instrument to load } \\
\text { or reposition needle }\end{array}$ & $\begin{array}{l}\text { Using fingers to load or } \\
\text { reposition needle }\end{array}$ \\
\hline Tying suture & $\begin{array}{l}\text { Needle is off or on driver } \\
\text { during tying, protected or } \\
\text { loose }\end{array}$ & $\begin{array}{l}\text { Needle is exposed while } \\
\text { tying suture, not loose }\end{array}$ \\
\hline Tissue retraction & $\begin{array}{l}\text { Using instrument to } \\
\text { retract wound edge when } \\
\text { using sharps }\end{array}$ & $\begin{array}{l}\text { Using hand/fingers to } \\
\text { retract wound edge } \\
\text { when using sharps }\end{array}$ \\
\hline Injection needle & $\begin{array}{l}\text { Injecting away from } \\
\text { hand/fingers, no } 2 \text {-handed } \\
\text { needle capping }\end{array}$ & $\begin{array}{l}\text { Injecting toward } \\
\text { hand/fingers, 2-handed } \\
\text { needle capping }\end{array}$ \\
\hline $\begin{array}{l}\text { Sharps placement } \\
\text { in field }\end{array}$ & $\begin{array}{l}\text { Placing sharps back onto } \\
\text { a neutral hands-free zone } \\
\text { while not in use }\end{array}$ & $\begin{array}{l}\text { Sharps left in operative } \\
\text { field unattended }\end{array}$ \\
\hline Passage of sharps & $\begin{array}{l}\text { Passing sharp with needle } \\
\text { in driver handle first, } \\
\text { scalpel handle first, use of } \\
\text { neutral hands-free zone }\end{array}$ & $\begin{array}{l}\text { Passing sharp with } \\
\text { needle exposed/blade } \\
\text { first }\end{array}$ \\
\hline $\begin{array}{l}\text { Verbal communication } \\
\text { about sharps }\end{array}$ & $\begin{array}{l}\text { Clear verbal notification } \\
\text { when passing sharps }\end{array}$ & $\begin{array}{l}\text { Unclear/no verbal } \\
\text { notification when } \\
\text { passing sharps }\end{array}$ \\
\hline
\end{tabular}

and each event scored separately (safe or unsafe). The number of safe events was then divided by the total number of events to give the mean safety performance score for specific tasks and overall score for the procedure. When the event could not properly be analyzed because of incomplete data, the event was not used for the safety analysis comparison. We analyzed data using descriptive statistics and the Mann-Whitney $U$ test.

\section{Results}

We obtained video data for 18 surgical residents: 14 general surgery residents (PGY-2) and 4 plastic surgery residents (PGY-1). In total (including incomplete data events), there were 1093 sharps-related events; of these, there was agreement between the 2 reviewers on the assessment of 1081 events (98.9\% concordance). For the videos of the 18 residents, overall sharps tasks were performed safely on average $69.2 \%$ (standard deviation [SD] 20.0\%) of the time, residents passed sharps in a safe manner $92.3 \%$ (SD $11.3 \%$ ) of the time, and verbal notification was used when passing $9.9 \%$ (SD 18.7\%) of the time. For $56.2 \%$ (SD $32.9 \%$ ) of suture needle manipulation tasks, surgical residents handled the suture needle in a safe manner, which translated to an average of 4.3 (SD 3.8) unsafe suture needle manipulations per case performed by the resident (Table 2). Most residents practised safe sharps techniques when tying sutures $(91.8 \%)$, retracting tissue $(85.2 \%)$ and using the injection needle (72.2\%). All residents demonstrated safe handling of the scalpel blade. In 18 videos, there was only 1 documented event of a sharp (a scalpel) left unattended in the surgical field. The mean number of personal sharps-related tasks for the resident was 15.6 per case, 5.3 of which were determined to be unsafe. There was a mean of 4.8 opportunities per case to communicate about sharps passage, and no verbal notification was given in $89.6 \%$ of these opportunities. We observed no actual injuries to the surgical resident or team.

On further analysis of verbal notification, there were 4.3 (SD 1.2) instances per case in which the surgical resident

Table 2. Summary of safe and unsafe personal sharps tasks for all videos of surgical residents, $n=18$

\begin{tabular}{|c|c|c|c|}
\hline \multirow[b]{2}{*}{ Sharps task } & \multicolumn{2}{|c|}{ Safety; mean (SD) } & \multirow{2}{*}{$\begin{array}{c}\% \text { safe, } \\
\text { mean (SD) }\end{array}$} \\
\hline & Safe & Unsafe & \\
\hline Personal sharps tasks & & & $69.2(20.0)$ \\
\hline Suture needle & $4.4(2.7)$ & $4.3(3.8)$ & 56.2 (32.9) \\
\hline Tying sutures & 3.7 (1.3) & $0.3(0.6)$ & $91.8(15.0)$ \\
\hline Tissue retraction & $1.8(0.8)$ & $0.4(0.7)$ & $85.2(27.9)$ \\
\hline Injection needle & $0.4(0.5)$ & $0.2(0.5)$ & $72.2(44.1)$ \\
\hline Passing of sharps & 3.7 (1.5) & $0.3(0.5)$ & $92.3(11.3)$ \\
\hline $\begin{array}{l}\text { Verbal communication } \\
\text { about sharps }\end{array}$ & $0.5(1.0)$ & $4.3(1.2)$ & $9.9(18.7)$ \\
\hline $\mathrm{SD}=$ standard deviation. & & & \\
\hline
\end{tabular}


failed to use verbal cues to alert team members when passing sharp instruments (Table 3 ). When evaluating team performance in verbal notification, scrub nurses gave verbal notification when passing sharp instruments $4.3 \%$ (SD $12.3 \%$ ) of the time compared with the attending surgeons (assistants), who notified $22.7 \%$ (SD 41\%) of the time. Overall, the surgical team used clear communication when a sharp was passed only $8 \%$ of the time. In 8 of 18 (44\%) procedures, no member ever communicated verbally regarding sharps passage. In 3 of 18 procedures, an HFT was used at some time.

We compared sharps-handling behaviour among PGY-2 general surgery residents with that of PGY-1 plastic surgery residents. Personal sharps tasks (see Table 1 for definitions) were safe in $74.4 \%$ (SD 18.4\%) of procedures performed by general surgery residents and in $50.9 \%$ (SD $14.8 \%$ ) of those performed by the plastic surgery residents. There was a significant increase in the safe suture needle manipulation performed by the general surgery residents compared with the plastic surgery residents, although overall personal sharps technique was not significantly safer (Table 4). Passage of sharps and verbal notification practices were similar between the groups.

Over the course of the study, we observed no clear trends with respect to resident performance of safe sharp tasks, safe passing and use of verbal notification (Table 5). Attending surgeons assisting on procedures showed greater compliance with safe passing of sharps over time (Table 6). Scrub nurses demonstrated safe sharps passing in all cases. Communication when passing sharps was not consistent in both groups.

Table 3. Summary of verbal notification when passing sharp instruments, comparing performance of scrub nurse,

surgical resident and surgical assistant, $n=18$

\begin{tabular}{|lccr|} 
& \multicolumn{2}{c}{ Safety; mean (SD) } & $\begin{array}{c}\text { \% safe, } \\
\text { OR team member }\end{array}$ \\
\cline { 2 - 3 } & Safe & Unsafe & \\
\hline Scrub nurse & $0.3(0.8)$ & $5.4(1.3)$ & $4.3(12.3)$ \\
\hline Surgical resident & $0.5(1.0)$ & $4.3(1.2)$ & $9.9(18.7)$ \\
\hline Surgical assistant & $0.2(0.4)$ & $0.6(0.7)$ & $22.7(41.0)$ \\
\hline OR = operating room; SD = standard deviation. & & \\
\hline
\end{tabular}

\section{Discussion}

While most junior surgical residents performing an open indirect inguinal hernia repair in the present study consistently passed sharp instruments in a safe manner (e.g., needle protected), an HFT was used in only 3 operations. The HFT is recommended by several professional organizations. ${ }^{2,5}$ Conflicting data regarding its efficacy in decreasing events exist. ${ }^{16,17}$ Supporting the use of an HFT, an uncontrolled prospective analysis demonstrated a decrease in the number of incidents of injuries and glove tears by $59 \%$ when an HFT was used. ${ }^{16}$ In contrast, a prospective randomized controlled trial of 156 operations did not demonstrate a difference in glove perforations when an HFT was used compared with cases where no HFT was used. ${ }^{17}$ It could be argued that our definition of safe passage of sharp instruments was too loose, as we only considered passage hand to hand, sharp end first and unprotected, to be unsafe. Studies indicate that $6 \%-16 \%$ of sharps injuries in the OR occur during hand-to-hand passing, even with protected sharps. ${ }^{7,18-20}$

When tasks relating to the manipulation of sharps were evaluated, residents only met safety standards $69.2 \%$ of the time. Most unsafe personal task events occurred when residents manipulated the suture needle with their fingers. This result is especially concerning given that studies have shown that suture needles pose the single greatest risk to OR staff, accounting for the vast majority of percutaneous injures in the OR, particularly when suturing muscle and fascia during wound closure. ${ }^{7,19}$ Traditionally, much of the focus for safety awareness campaigns has been on hollow bore needle stick injury prevention; however, increased emphasis should be placed on suture needle manipulation. Training surgeons should be instructed to manipulate suture needles with an instrument if possible to target the riskiest behaviour causing these injuries.

Clear communication between surgical team members when sharps are being moved is a consistent recommendation of many organizations, including the American College of Surgeons, the American Operating Room Nurses Association and the Center for Disease Control. 2,4,5 Despite the emphasis on this factor, literature measuring this facet

Table 4. Mean safety performance of PGY-2 general surgery residents $(n=14)$ compared with PGY-1 plastic surgery residents $(n=4)$

\begin{tabular}{|c|c|c|c|c|c|c|c|}
\hline \multirow{3}{*}{$\begin{array}{l}\text { Sharps task } \\
\text { Personal sharps tasks }\end{array}$} & \multicolumn{3}{|c|}{ PGY-2 general surgery; mean (SD) } & \multicolumn{3}{|c|}{ PGY-1 plastic surgery; mean (SD) } & \multirow[b]{2}{*}{$p$ value } \\
\hline & Safe & Unsafe & $\%$ safe & Safe & Unsafe & $\%$ safe & \\
\hline & & & $74.4(18.4)$ & & & $50.9(14.8)$ & \\
\hline Tying sutures & $3.6(1.3)$ & $0.3(0.6)$ & $92.3(16.2)$ & $4.3(1.3)$ & $0.5(0.6)$ & 90.0 & 0.76 \\
\hline Tissue retraction & $1.8(0.8)$ & $0.4(0.8)$ & $83.3(30.7)$ & $1.8(1.0)$ & $0.3(0.5)$ & $91.7(16.7)$ & 0.49 \\
\hline Injection needle & $0.4(0.5)$ & $0.3(0.6)$ & $64.3(47.6)$ & $0.5(0.6)$ & $0.0(0.0)$ & $100.0 \quad(0.0)$ & 0.09 \\
\hline
\end{tabular}


of OR sharps culture is lacking. In the present study, a minority of residents verbally notified team members when passing sharp instruments. The underutilization of verbal notification was observed among all surgical team members, and in 8 of the 18 procedures assessed no notification was given by any team member when sharps were passed.

Two universal recommendations by the American College of Surgeons in preventing unsafe sharps-handling practices include double gloving and the use of blunt suture needles. ${ }^{21}$ However, in our study, we were not able to accurately assess whether double gloving was used, and our institution did not have blunt suture needles available during the study period.

Throughout surgical training decreased rates of sharps exposure have been documented, with a much lower incidence of percutanoeus injury among senior surgical residents than among more junior trainees. ${ }^{8}$ In a study of surgical residents by Makary and colleagues, ${ }^{6} 59 \%$ of respondents indicated that they experienced a sharps injury during medical school. It appears that early in the academic year, residents are more at risk. In a study at a teaching institution, most sharps injuries occurred in the first 3 months of the academic year. ${ }^{22}$ Education about safe sharps behaviour and injury prevention is most effective early on to ensure durable practices. ${ }^{23}$ In addition, given that most injuries occur at the beginning of the academic year, safe sharps education should be timed accordingly. Though we found PGY-2 residents do have improved suture needle manipulation technique compared with PGY-1 residents, other parameters were not significantly different between the groups. Our study emphasizes the importance of education and prevention strategies

Table 5. Summary of average safe sharps tasks, safe passing and use of verbal notification while passing sharps for surgical residents, by year, $n=18$

\begin{tabular}{|lccccccc|} 
& & \multicolumn{5}{c|}{ Sharps task; \% (SD) } \\
\cline { 3 - 8 } Year & Nesidents & Safe sharps tasks & \multicolumn{3}{c|}{ Safe passing } & Verbal notification \\
\hline 2002 & 4 & 74.2 & $(21.7)$ & 87.5 & $(16)$ & 31.3 & $(27.5)$ \\
\hline 2003 & 5 & $63.3(23.2)$ & 88.8 & $(13.1)$ & 0.0 & $(0)$ \\
\hline 2004 & 4 & $83.6(17.2)$ & 95.5 & $(10)$ & $8.3(16.7)$ \\
\hline 2005 & 5 & $59.5(13.8)$ & 100 & $(0)$ & 4.0 & $(8.9)$ \\
\hline
\end{tabular}

Table 6. Summary of average safe passing and use of verbal notification while passing sharps for assistants (attending surgeons) and scrub nurses, by year, $n=18$

\begin{tabular}{|c|c|c|c|c|c|c|}
\hline \multirow{3}{*}{$\begin{array}{l}\text { Year } \\
2002 \\
\end{array}$} & \multicolumn{4}{|c|}{ Safe passing; \% (SD) } & \multicolumn{2}{|c|}{ Sharps communication; \% (SD) } \\
\hline & \multicolumn{2}{|c|}{ Assistant } & \multicolumn{2}{|c|}{ Scrub nurse } & Assistant & \multirow{2}{*}{$\begin{array}{c}\text { Scrub nurse } \\
12.5(25)\end{array}$} \\
\hline & 0.0 & (0) & 100 & (0) & $0.0 \quad(0)$ & \\
\hline 2003 & 66.7 & (57.7) & 100 & (0) & $3.3 \quad(7.5)$ & $3.3 \quad(7.5)$ \\
\hline 2004 & 100 & (0) & 100 & (0) & $0.0(0)$ & $0 \quad(0)$ \\
\hline 2005 & 100 & (0) & 100 & (0) & $25.0(50)$ & 2.2 (5) \\
\hline
\end{tabular}

for sharps injuries among surgical trainees, especially early and ongoing in their training.

The literature on decreasing sharps exposure and improving reporting among surgical residents is sparse. Brasel and colleagues ${ }^{8}$ sought to determine whether mandatory safety training influenced self-reporting of sharps injuries in the OR. They retrospectively reviewed occupational health records of percutaneous OR exposures, intervened with enhanced training, including instructional rounds supplemented by a videotape. Injury reports were then prospectively surveyed, and no difference was noted in between the preintervention and the enhanced training groups. ${ }^{8}$ Over our study period, no such education or interventions occurred either in the context of resident education or OR policy.

\section{Limitations}

There are several limitations to our study. First, data was gathered by retrospective review of videotaped procedures to assess technical performance and not safety performance. It is also possible that a Hawthorne effect altered the behaviour of residents and staff such that the results do not truly represent their typical sharps-handling techniques. The residents were especially aware that they were being videotaped, and that awareness may have changed their behaviour. In addition, because of limited view, there were occasions during the surgeries in which we were not able to evaluate the sharps-handling behaviour. We assumed there would be evenly distributed safe and unsafe missed events for the purposes of data evaluation, although this is probably unlikely given the data generated. We attempted to minimize the bias of a single reviewer by duplicate review of the videos to record the sharps events and by rereview of each identified event by a second reviewer to determine if the event was, first, sharps-related and, second, safe or unsafe. It is possible that there were sharps-related tasks not identified by the first review and, as a result, were not evaluated by the second reviewer. However, given the standard approach (and the typical timing of scalpel use, suture and injection sharps) to pediatric inguinal hernia repairs, we felt that the likelihood of missing a substantial number of sharps events would be low. When comparing the performance between PGY-2 general surgery residents and PGY-1 plastic surgery residents, the difference in safe suture needle manipulation could be related to resident experience, specialty training or other factors.

\section{Conclusion}

Currently, there is no formal education of surgical residents in our institution about safe sharps practices in the OR. Explicit instruction about sharps-handling technique combined with feedback on sharps handling in the form of 
video review could provide an opportunity for improved sharps awareness and ultimately the prevention of sharpsrelated injury. As a result of our analysis of surgical trainees, an educational video has been created to educate junior surgical residents about safe and unsafe practices (available at http://youtu.be/toPXGBc6qfA). The intention of this video is to initiate discussion and awareness of safe sharpshandling practices. We echo the comment by Bakaeen and colleagues $^{9}$ that in the OR blood exposure prevention strategies should be directed at safety within the surgical field and focus beyond hollow-bore needle stick injuries to include education, mentoring and competency training. The process of training a safe surgeon requires not only that they have the technical ability to skillfully perform the correct procedure on the correct patient, but also that they are aware of - and take responsibility for - sharps to ensure protection of themselves and their surgical team.

Acknowledgements: We thank Damian Duffy and the Office of Pediatric Surgical Evaluation and Innovation at BC Children's Hospital for funding and support.

Competing interests: None declared.

Contributors: G.K. Blair and S. Butterworth designed the study. All authors acquired the data, reviewed the article and approved its publication. D. Tso and S. Butterworth analyzed the data and wrote the article.

\section{References}

1. AORN position statement on workplace safety. In: Perioperative standards and recommended practices. Denver (CO): Association of Perioperative Registered Nurses; 2004. p. 169-71.

2. Centers for Disease Control and Prevention (CDC). Workbook for designing, implementing, and evaluating a sharps injury prevention program. Atlanta (GA): CDC; 2008. Available: www.cdc.gov/sharpssafety /pdf/sharpsworkbook_2008.pdf (accessed 2010 March 21).

3. Patterson JM, Novak CB, Mackinnon SE, et al. Surgeon's concern and practices of protection against blood borne pathogens. Ann Surg 1998;228:266-72.

4. Berguer R, Heller PJ. Preventing sharps injuries in the operating room. 7 Am Coll Surg 2004;199:462-7.

5. Association of periOperative Registered Nurses. AORN guidance statement: sharps injury prevention in the perioperative setting. AORN F 2005;81:662, 665-6, 669-71.

6. Makary MA, Al-Attar A, Holzmueller CG, et al. Needlestick injuries among surgeons in training. N Engl 7 Med 2007;356:2693-9.

7. Jagger J, Bentley M, Tereskerz P. A study of patterns and prevention of blood exposures in OR personnel. AORN F 1998;67:979-81, 983-4, 986-7 passim.
8. Brasel KJ, Mol C, Kolker A, et al. Needlesticks and surgical residents: who is most at risk? I Surg Educ 2007;64:395-8.

9. Bakaeen F, Awad S, Albo D, et al. Epidemiology of exposure to blood borne pathogens on a surgical service. Am F Surg 2006;192:e18-21.

10. Perry J, Parker G, Jagger J. EPINet Report: 2006 percutaneous injury rates. International Healthcare Worker Safety Center 2009;1:1-4. Available: http://www.healthsystem.virginia.edu/pub/epinet /2006epinetreport.pdf/view (accessed 2012 June 18).

11. Guimet M, Mendicino S, Rockett MS. Percutaneous injuries in a high-volume podiatric surgical residency program. 7 Foot Ankle Surg 2001;40:15-20.

12. Sherer LA, Chang MC, Meredith JW, et al. Videotape review leads to rapid and sustained learning. Am F Surg 2003;185:516-20.

13. Ward M, MacRae H, Schlachta C, et al. Resident self-assessment of operative performance. Am F Surg 2003;185:521-4.

14. Aggarwal R, Grantcharov T, Moorthy K, et al. Toward feasible, valid, and reliable video-based assessments of technical surgical skills in the operating room. Ann Surg 2008;247:372-9.

15. Goldman LI, Maier WP, Rosemond GP, et al. Teaching surgical technique by the critical review of videotaped performance - the surgical instant replay. Surgery 1969;66:237-41.

16. Stringer B, Infante-Rivard C, Hanley JA. Effectiveness of the handsfree technique in reducing operating theatre injuries. Occup Environ Med 2002;59:703-7.

17. Eggleston MK Jr, Wax JR, Philput C, et al. Use of surgical pass trays to reduce intraoperative glove perforations. 7 Matern Fetal Med 1997; 6:245-7.

18. Quebbeman EJ, Telford GL, Hubbard S, et al. Risk of blood contamination and injury to operating room personnel. Ann Surg 1991;214: 614-20.

19. Tokars JI, Bell DM, Culver DH, et al. percutaneous injuries during surgical procedures. FAMA 1992;267:2899-904.

20. Wright JG, McGreer AJ, Chyatte D, et al. Mechanisms of glove tears and sharp injuries among surgical personnel. FAMA 1991;266:1668-71.

21. [ST-58] Statement on sharps safety. Chicago (IL): American College of Surgeons; 2007. Available: www.facs.org/fellows_info/statements/st-58 .html (accessed 2009 June 24).

22. Leyden A. Needlestick injures in medical residents: a model for prevention. In: Proceedings of the National Sharps Injury Prevention Meeting; 2005 Sept. 12; Atlanta, Ga. Atlata (GA): Centers for Disease Control and Prevention (CDC); 2005 p. 19-21. Available: cdc.gov /sharpssafety/pdf/proceedings.pdf (accessed 2010 Aug. 4).

23. Holodnick CL, Barkaukas V. Reducing percutaneous injuries in the OR by education methods. AORN f 2000;72:461-4, 468-72, 475-6. 